\title{
0 enfermeiro diante da burocracia da qualidade e produtividade no ambiente hospitalar
}

\author{
The nurse in face of the bureaucracy of quality and productivity in the hospital environment
}

\author{
José Angelo Leal Braga"
}

\begin{abstract}
Sociedade Brasileira de Terapia Intensiva (Sobrati), Faculdades Unificadas Serra dos Órgãos (Unifeso), Teresópolis, Rio de Janeiro, Brasil. *Autor para correspondência. E-mail: joseangelo.braga@hotmail.com
\end{abstract}

\begin{abstract}
Resumo: A atuação do enfermeiro como administrador hospitalar é uma tarefa complexa e que tem por objetivo implementar ações para lucro e desenvolvimento nas instituições, otimizando a burocracia, promovendo recursos para melhoria da produtividade com qualidade. Este estudo descreve de uma forma qualitativa as teorias da administração, recursos utilizados para reduzir a burocracia, aumentando a gestão da qualidade, o papel do enfermeiro como administrador hospitalar, com uma nova abordagem gerencial.
\end{abstract}

Palavras-chave: enfermeiro, administração hospitalar, qualidade, produtividade.

\begin{abstract}
The role of the nurse as a hospital administrator is a complex task that aims to implement actions for profit and development in institutions, optimizing bureaucracy, promoting resources to improve productivity with quality. This study describes qualitatively the theories of administration, resources used to reduce bureaucracy, increasing quality management, the role of nurses as hospital administrators, with a new managerial approach.
\end{abstract}

Keywords: nurse, hospital administration, quality, productivity.

\section{Introdução}

A administração é uma ciência social aplicada, fundamentada em um conjunto de normas e funções elaboradas para disciplinar elementos de produção. A administração estuda os empreendimentos humanos com o objetivo de alcançar um resultado eficaz e retorno financeiro de forma sustentável e com responsabilidade social, ou seja, é impossível falar em "administração" sem falar em objetivos. Em síntese, o administrador é a ponte entre os meios (recursos financeiros, tecnológicos e humanos) e os fins (objetivos). Como elo entre os recursos e os objetivos de uma organização, cabe ao administrador combinar os recursos na proporção adequada e para isso é necessário tomar decisões constantemente num contexto de restrições, pois, nenhuma organização por melhor que seja dispõe de todos os recursos e também a capacidade de processamento de informações do ser humano é limitado. Administrar envolve a elaboração de planos, pareceres, relatórios, projetos, arbitragens e laudos, em que é exigida a aplicação de conhecimentos inerentes às técnicas de Administração.

A administração recebeu influências de diversas áreas do conhecimento humano. A Filosofia deu sua grande contribuição para a administração. Já antes de Cristo, os filósofos da antiguidade expunham seu ponto de vista sobre esta área fascinante que viria a ser importante nos dias atuais. Sócrates (470 a.C.- 399 a.C.), citado por Chiavenato (1997) afirmou que a administração é uma habilidade pessoal separada do conhecimento técnico e da experiência.

Sobre qualquer coisa que um homem possa presidir, ele será, se souber do que precisa e ser for capaz de provê-lo, um bom presidente, quer tenha a direção de um coro, uma família, uma cidade ou um exército. Não é também uma tarefa punir os maus e honrar os bons? Portanto, Nicomaquides, não desprezeis homens hábeis em administrar seus haveres; pois os afazeres privados difere dos públicos somente em magnitude; em outros aspectos, são similares, mas o que mais se deve observar é que nenhum deles pode ser gerido sem homens, nem os afazeres privados são geridos por uma espécie de homem e os públicos por outra: pois aqueles que conduzem os negócios públicos não utilizam homens de natureza diferentes daqueles empregados pelos que gerem negócios privados; e os que sabem empregá-los conduzem tanto os negócios públicos quanto os privados, judiciosamente, enquanto aqueles que não sabem errarão na administração de ambos. (SÓCRATES 470 a.C. - 399 a.C.), citado por Chiavenato (1997). 
Lendo as literaturas, artigos e revistas relacionadas ao assunto percebe-se que os profissionais têm quase ou nenhuma preocupação com relação a essa problemática toda. Falar sobre esse assunto será de grande importância para os trabalhadores da área da saúde e futuros pesquisadores desse assunto, explorar o assunto poderá ter resultados positivos para todos.

Além disso, a pesquisa tem várias contribuições como:

$\mathrm{Na}$ área da pesquisa serão consideráveis onde serão oferecidos dados para futuros estudos relacionados sobre o tema em questão abrangendo ainda mais a saúde do profissional de enfermagem. Lembrando que durante a realização do estudo da arte conseguiu-se os objetivos de estudo relacionando que se tem disponível em produção cientifica.

Outra contribuição importante é o aspecto do ensino, onde a produção permitirá que docentes e alunos adquiram conhecimento e também a aplicabilidade na pratica profissional para a assistência ao receber grandes contribuições, pois, o enfermeiro está presente em tempo integral e assim poderá disseminar os conhecimentos dentro da sua unidade de trabalho através da observação do trabalhador.

Portanto este estudo teve como objetivo geral, conhecer a administração hospitalar exercida pelo enfermeiro como também analisar a burocracia e a produtividade nas unidades hospitalares. E teve como objetivo específico, descrever sobre o desempenho do enfermeiro diante da burocracia da qualidade e produtividade

\section{Metodologia}

Para o desempenho dessa pesquisa será por uma abordagem de natureza qualitativa, permitindo entrar na essência do tema sugerido. A pesquisa qualitativa concede interpretar as representações de um determinado grupo e compreender o valor cultural que estes colaboram a determinados temas.

Optou-se por um levantamento bibliográfico sobre o tema em questão nos bancos de dados informatizados MEDLINE, LILACS, SCIELO, e consulta manual em periódicos da área, publicados nos últimos dez anos. De posse do material foi realizada uma leitura do tipo exploratória que tem por objetivo investigar, em que medida a obra examinada interessa ao estudo, nesse momento alcançou um maior entendimento com o tema da investigação.

A próxima etapa constará da determinação do material de interesse a pesquisa, realizando uma leitura seletiva. Assim os textos foram lidos a fim de reconhecer sua relação com o objetivo do estudo.

\section{Desenvolvimento Teórico}

Ao longo de nossas vidas fazemos parte de alguma organização. Estas organizações podem ser formais ou informais. Ambas as organizações que fazemos parte durante a vida tem objetivos e metas a serem cumpridas e definem métodos, verbas, prazos e procedimentos que permite vislumbrar os objetivos a serem alcançados.

O termo administração vem do latim, ad (junto de) e ministratio (prestação de serviço), portanto, administração é uma ação de prestar um serviço. Contemporaneamente, administração não é somente relacionado ao governo ou a condução de uma empresa, e sim todas as atividades que envolvem planejamento, organização, direção e controle.

A tarefa da administração é a de interpretar os objetivos propostos pela organização e transformá-los em ação organizacional por meio de planejamento, organização, direção e controle de todos os esforços realizados em todas as áreas e em todos os níveis da organização, a fim de alcançar tais objetivos de maneira mais adequada à situação. Chiavenato (1997).

Existem alguns aspectos em comum nas organizações, mas existe um que é essencial, toda e qualquer organização é formada de pessoas que a administram e uma depende da outra. As organizações estão inseridas na nossa vida e é essencial a ela. As empresas servem os indivíduos que fazem parte de uma sociedade, fornecem-nos e preserva o conhecimento e proporcionam carreira. O termo administração vem do latim, ad (junto de) e ministrativo (prestação de serviço), portanto, administração é uma ação de prestar um serviço. Contemporaneamente, administração não é somente relacionado ao governo ou a condução de uma empresa, e sim todas as atividades que envolvem planejamento, organização, direção e controle.

Desde os primórdios, o homem se associou a outros para conseguir atingir seus objetivos. O homem, portanto, aprendeu, desde cedo que precisava de outro homem para trabalhar em conjunto e atingir determinadas metas, que modificou completamente a estrutura social e comercial da época, provocando profundas mudanças. Deste trabalho em conjunto surgiram as empresas rudimentares, que datam da época dos assírios, babilônicos, fenícios, egípcios, gregos e romanos. Mas, a história da administração é recente, e surge com o aparecimento das grandes corporações. Foi a revolução industrial, que provocou o aparecimento 
de grandes empresas e da moderna administração. A revolução industrial até hoje influencia as empresas. A revolução industrial iniciou na Inglaterra por volta do ano 1776, com a aplicação da máquina a vapor no processo de produção. Segundo Chiavenato (1989) a revolução industrial se desenvolveu em duas épocas distintas:

- Primeira época: (1780-1860). Carvão como primeira fonte de energia e o ferro como principal matériaprima, e;

- Segunda época: (1860-1914). A revolução da eletricidade e derivados do petróleo.

- O crescimento acelerado e desorganizado das empresas, e;

- Necessidade de maior eficiência e produtividade das empresas.

Segundo Stoner (1999) Administração é o processo de planejar, organizar, liderar e controlar os esforços realizados pelos membros da organização e o uso de todos os outros recursos organizacionais para alcançar os objetivos estabelecidos. Processo é algo sistemático e todos os administradores participam de alguma forma de processos sistemáticos. Entende-se um processo complexo, quando ele é descrito como em séries separadas. Este tipo de descrição é conhecida como modelos.

Segundo Stoner (1999) modelo é uma simplificação do mundo real, usada para demonstrar relacionamentos complexos em termos fáceis de serem entendidos. Quando falamos de planejar, organizar, direcionar e controlar estamos falando em um modelo que foi desenvolvido pela administração no século XIX e que ainda é usado hoje. Portanto o modelo no processo administrativo é: planejamento, organização, direção e controle. Só que na prática este modelo não acontece sozinho, e sim de forma interativa, onde todos os passos interagem no processo administrativo.

\section{A Informatização Hospitalar}

Freitas (1994) define informação como sendo "um dado que tem significado ou utilidade para o destinatário, ou seja, são dados processados para uma forma que tenha significado para o receptor, alterando as suas expectativas ou a sua visão sobre as alternativas que estão disponíveis”. Tecnologia da informação é o "conjunto de recursos não-humanos (hardware e software) dedicados ao armazenamento, processamento e comunicação da informação e o modo pelo qual esses recursos são organizados em um sistema capaz de efetuar um conjunto de tarefas."

Ortiz (1997) faz uma observação importante com relação à concepção dos sistemas de informação (SI): “a informação representa dados em uso e este uso implica usuários e, portanto, o sistema deve identificar quem necessita qual informação e quando, onde e como a informação é necessária. A concepção de um SI, portanto, não pode ser conduzida, unicamente, por profissionais de informática. Essa tarefa demanda alto nível de participação e de controle dos usuários finais. As necessidades e exigências do usuário devem dirigir os esforços de construção do SI.

Segundo Torres (1995) uns dos principais impactos da tecnologia da informação é a sua capacidade de integração, tanto no nível interno da organização quanto no nível de integração Inter organizacional. $O$ autor cita que, uma vez estabelecidos os objetivos básicos da organização, cada uma das áreas funcionais e gerenciais pode ser questionada sobre suas contribuições específicas para com esses objetivos e, em seguida, são identificadas as possibilidades de usos das tecnologias de informações que possam dar apoio ou facilitar a realização das contribuições ou metas específicas e, portanto, dos objetivos da organização.

Em artigo para a Folha de S. Paulo, o professor Ortiz (1997) diferencia a informática e a informação com relação ao conhecimento. No mundo moderno, a tecnologia da informação virou uma espécie de fetiche generalizado, o que não é verdade, pois a informática é necessária, sem dúvida, mas não é suficiente. Segundo ele:

“O conceito de informação desloca a noção de conteúdo para o plano secundário. Por isso, ela não é cumulativa, como o conhecimento. Pode-se estocá-la na memória computadorizada das máquinas, mas cada unidade permanece intacta na sua descrição solitária. O fato de eu possuir mais ou menos informações armazenadas não implica necessariamente maior ou menor conhecimento das coisas."

Com relação à informatização aplicada no ambiente hospitalar, exploramos inicialmente os conceitos de Stumpf e Freitas, (1997) em estudo realizado em um hospital universitário de Porto Alegre, devido à adequação à realidade brasileira; em seguida, serão citados outros autores, principalmente da Inglaterra. 
O estudo de Stumpf e Freitas (1997) teve como objetivo definir o conteúdo essencial do Prontuário de Pacientes, em projeto para o Hospital de Clínicas de Porto Alegre, hospital-escola da Universidade Federal do Rio Grande do Sul.

Laudon e Laudon (1997), citado nesse artigo, entendem que a introdução ou alteração de sistemas de informação tem profundo impacto ambiental e organizacional. Transforma o modo pelo qual os diversos grupos atuam e interagem, mudando a maneira pela qual a informação é definida, "acessada" e usada para administrar os recursos da organização e, frequentemente, leva à nova distribuição de autoridade e de poder. O envolvimento do usuário na concepção e na operação dos sistemas de informação tem várias consequências positivas. O usuário, além de ter mais oportunidades para moldar os sistemas de acordo com suas prioridades e necessidades, estará mais apto a reagir positivamente ao sistema, porque teve participação ativa na sua definição e desenvolvimento.

Miranda (1992) realizou estudo sobre o impacto da implementação da Tecnologia da Informação no Hospital das Clínicas da Universidade de São Paulo e concluiu que as mudanças introduzidas devem ser bem administradas e que a motivação e a participação dos usuários dos sistemas são fundamentais para o sucesso deles. Com relação à implantação dos sistemas de informação em hospitais,

Peterson e Jelger (1988) consideraram o problema da integração das informações hospitalares, sugerindo que a informação deveria entrar no sistema uma vez apenas e tornar-se disponível para todos que dela necessitassem. Surgiu, nos anos 70, o conceito de interligar as diferentes partes do hospital, mas o fenômeno que se observou foi a criação de ilhas de informatização, ou seja, vários sistemas isolados e sem conexão, desenvolvidos por diferentes equipes, causando redundância de dados e sua absoluta falta de integração.

Ward (1997) salienta também que a informatização não resolve os problemas, porém pode auxiliar uma administração eficiente, dando alguns exemplos de informações que são necessárias: histórico dos pacientes, sistemas de comunicação e divulgação, protocolos multidisciplinares, informações para pacientes e acompanhantes, administração de leitos e desempenho do planejamento. Alguns problemas na informatização do sistema de enfermagem foram evidenciados:

- Muito tempo e esforço envolvidos: não apenas no desenvolvimento de um sistema original, mas na garantia de que o atendimento corrente seja registrado;

- Planos de assistência são difíceis de usar: são geralmente muito longos, exigindo inúmeros relatórios e levando o resultado a um aumento do volume de papel

- Os terminais de computador tiram as enfermeiras da assistência direta ao paciente;

- O plano de assistência, geralmente, não é individualizado e a informática não é necessariamente utilizada;

- O paciente é dificilmente envolvido: apesar de algumas áreas tentarem introduzir terminais aos leitos, isto não levou à participação do paciente;

- Restrição do aprendizado e de oportunidades para refletir sobre as práticas;

- Os planos de assistência são usados para a padronização, ou seja, são geralmente listas de tarefas, não valorizando a assistência individualizada.

Segundo Earl (1989) os sistemas de informação são as informações utilizadas para a administração dos serviços. O autor parte deste conceito para definir tecnologia da informação como sendo um dos meios para a melhoria dos sistemas de informação.

\section{Teorias da Administração}

A teoria geral da administração começou com a ênfase nas tarefas, com a administração científica de Taylor. A seguir, a preocupação básica passou para a ênfase na estrutura com a teoria clássica de Fayol e com a teoria burocrática de Max Weber, seguindo-se mais tarde a teoria estruturalista. A reação humanística surgiu com a ênfase nas pessoas, por meio da teoria comportamental e pela teoria do desenvolvimento organizacional. A ênfase no ambiente surgiu com a Teoria dos Sistemas, sendo completada pela teoria da contingência. Esta, posteriormente, desenvolveu a ênfase na tecnologia. Cada uma dessas cinco variáveis tarefas, estrutura, pessoas, ambiente e tecnologia - provocou a seu tempo uma diferente teoria administrativa, marcando um gradativo passo no desenvolvimento da TGA. Cada teoria administrativa procurou privilegiar ou enfatizar uma dessas cinco variáveis, omitindo ou relegando a um plano secundário todas as demais. 


\begin{tabular}{|c|c|c|}
\hline Ênfase & Teorias administrativas & Principais enfoques \\
\hline Tarefas & Administração científica & Racionalização do trabalho no nível operacional \\
\hline \multirow{3}{*}{ Estrutura } & $\begin{array}{c}\text { Teoria clássica } \\
\text { Teoria neoclássica }\end{array}$ & $\begin{array}{l}\text { Organização Formal; } \\
\text { Princípios gerais da Administração; } \\
\text { Funções do Administrador }\end{array}$ \\
\hline & Teoria da burocracia & $\begin{array}{l}\text { Organização Formal Burocrática; } \\
\text { Racionalidade Organizacional; }\end{array}$ \\
\hline & Teoria estruturalista & $\begin{array}{l}\text { Múltipla abordagem: } \\
\text { Organização formal e informal; } \\
\text { Análise intra organizacional e análise Inter organizacional; }\end{array}$ \\
\hline \multirow{3}{*}{ Pessoas } & Teoria das relações humanas & $\begin{array}{l}\text { Organização informal; } \\
\text { Motivação, liderança, comunicações e dinâmica de grupo; }\end{array}$ \\
\hline & Teoria comportamental & $\begin{array}{c}\text { Estilos de Administração; } \\
\text { Teoria das decisões; Integração dos objetivos organizacionais e } \\
\text { individuais; }\end{array}$ \\
\hline & Teoria do desenvolvimento organizacional & $\begin{array}{c}\text { Mudança organizacional planejada; Abordagem de sistema } \\
\text { aberto; }\end{array}$ \\
\hline \multirow{2}{*}{ Ambiente } & $\begin{array}{l}\text { Teoria estruturalista } \\
\text { Teoria neoestruturalista }\end{array}$ & $\begin{array}{l}\text { Análise intraorganizacional e análise ambiental; } \\
\text { Abordagem de sistema aberto; }\end{array}$ \\
\hline & Teoria da contingência & $\begin{array}{l}\text { Análise ambiental (imperativo ambiental); } \\
\text { Abordagem de sistema aberto; }\end{array}$ \\
\hline Tecnologia & Teoria dos sistemas & Administração da tecnologia (imperativo tecnológico); \\
\hline
\end{tabular}

Fonte: Wikipédia, 2008.

\section{Pirâmide da Administração}

Maslow propõe uma hierarquia de motivos compartilhados por todos. Quando se fala em motivos, não se pode deixar de mencionar o constructo de Freud, envolvendo os três componentes mais básicos do indivíduo: $\mathrm{O}$ id, o ego e o superego. O id é o reino dos instintos, dos impulsos mais básicos do indivíduo. Como parte desses impulsos são antissociais, é necessário que haja um controlador para eles. Tal é a tarefa do ego. O ego é o dirigente das atividades realizadas pelo indivíduo em suas rotinas diárias, assegurando que seu comportamento seja socialmente aceitável. O superego, enfim, é o sensor do comportamento do indivíduo, avaliando, julgando e punindo a violação das normas de conduta.

Os motivos das ações humanas, mesmo aqueles tão simples, como a fome, encontram-se associados a cada um desses níveis na estrutura da personalidade. No que se refere ao comportamento de compra, podem-se associar determinados motivos a cada um destes níveis. A compra de produtos de status está, muitas vezes, associada à atuação do superego.

Segundo Maslow, as pessoas tinham necessidades a serem satisfeitas, e que estas necessidades estavam elencadas numa hierarquia, e que uma pessoa só poderia subir na hierarquia para a necessidade número dois se primeiro ela tivesse satisfeita a necessidade número um. Na base desta hierarquia estão as necessidades fisiológicas e de seguranças e no topo da hierarquia estão as necessidades do ego e as de autorrealização. $\mathrm{O}$ que Maslow propunha, é que as necessidades da base necessitam ser satisfeitas para se atender as necessidades do topo da hierarquia.

Maslow tentou explicar em seus ensaios científicos, o por que as pessoas são dirigidas por certas necessidades e afirmou que o que motiva as pessoas a agir são as necessidades não atendidas. Mas hierarquizou as necessidades humanas, parte das necessidades mais urgentes às menos urgentes. A hierarquia das necessidades de Maslow é distribuída segundo a figura abaixo.

De acordo com a teoria, as pessoas tentam primeiro satisfazer as necessidades da base da hierarquia. Somente quando estas necessidades são satisfeitas, as pessoas movem-se para o atendimento das necessidades de categorias superiores. Maslow não distingue entre necessidades e desejos. De acordo com essa distinção, somente os dois primeiros níveis - fisiológico e segurança - são necessidades, ao passo que os últimos três são desejos. 


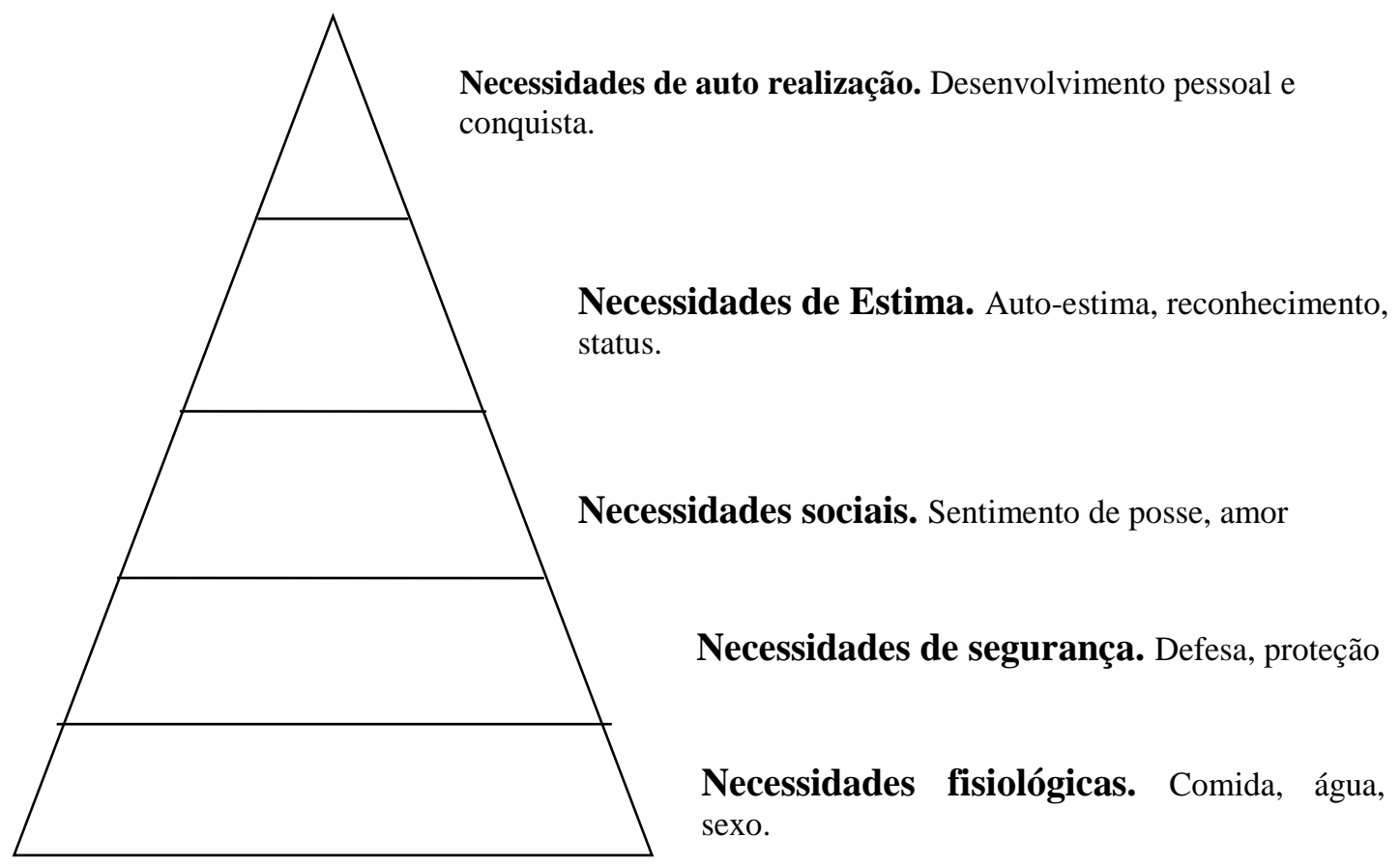

\section{O Papel do Administrador Hospitalar}

$\mathrm{Na}$ organização hospitalar existe uma constante renovação na área técnica/médica. Porém, na área administrativa, o mesmo não ocorre com tanta frequência, o que provoca uma acomodação do administrador em busca de mudanças das rotinas de trabalho. Para se exercer a função de gestor hospitalar, é necessário: saber coordenar as atividades para se atingir os objetivos; promover programas de capacitação dos profissionais para acompanhar as inovações, pois sem renovação o hospital irá declinar e morrer; promover a motivação do pessoal para trabalhar com entusiasmo. E cabe ao diretor dar o exemplo de dedicação ao serviço.

Atualmente a administração hospitalar é uma das mais complexas, não apenas pela nobreza e amplitude da sua missão, mas, sobretudo, por apresentar uma equipe multidisciplinar com elevado grau de autonomia, para dar assistência à saúde em caráter preventivo, curativo e reabilitador a pacientes em regime de internação, onde se utiliza tecnologia de ponta de rotina e crescentemente. E se constitui, ainda, num espaço de prática de ensino-aprendizagem e produção científica (Azevedo, 1993).

O diretor deve ser um hábil negociador, de forma que os profissionais pensem no hospital como uma instituição estável que deve durar muitas gerações e que seja um multiplicador e acelerador de benefícios sociais e econômicos. Quando o administrador se insere na instituição de saúde e começa a compreender como atuam os profissionais da área e como funcionam as suas inter-relações, a depender da sua capacidade profissional, poderá não ter êxito. Considerando-se que o processo de formação encontra-se em fase de construção e que os hospitais são gerenciados por vários tipos de profissionais, é que se procura investigar o perfil desse administrador e quais competências (conhecimentos, habilidades e atitudes) ele deve ter. A princípio, a literatura afirma que ele precisa ter o perfeito entendimento do processo de trabalho na área da saúde, com uma visão integrada de todos os serviços, autonomia e iniciativa para decidir, apoiado nos princípios éticos, estar comprometidos com a empresa, saber trabalhar com equipe multiprofissional e estar disposto a aprender diariamente.

Os administradores hospitalares colocam que, nas suas práticas gerenciais, tudo é negociado e envolve a participação de seus subordinados. Já com relação aos seus superiores, a maioria afirma que a negociação e a participação são mais restritas. O papel de facilitador, catalisador e líder ainda está perdendo para o de centralizador e chefe, como colocado por Fayol.

O papel do administrador de alto nível envolve as seguintes capacidades: estratégica, racionalidade administrativa e habilidades interpessoais de liderança e de tomada de decisão, como colocado por Motta (2002) que, de certa forma, não vêm sendo plenamente assimiladas pelos gestores entrevistados, de acordo com suas respostas. 
Motta (2002) coloca a importância do conhecimento por parte do dirigente, das dimensões formais e previsíveis do processo decisório organizacional, enfocando:

- As formas de divisão e especialização do trabalho, bem como a distribuição do poder e da autoridade para melhor utilizar os recursos disponíveis;

- A maneira de captar, processar e analisar informações externas e internas para melhor agir na formulação de políticas, estratégias organizacionais e na solução de problemas;

- As alternativas de definição de processos sequenciais interdependentes que levam ao alcance de resultados, para poder atuar na coordenação e no controle;

- As formas comportamentais humanas - individuais e grupais - que se estabelecem em uma organização de trabalho, para saber que ações gerenciais produzem respostas comportamentais mais adequadas;

Burmester e Richard (1995), estudiosos do tema, colocam que uma das dificuldades na administração em hospitais brasileiros decorre do imobilismo. O imobilismo surge de "comportamentos nascidos de uma vontade de não 'fazer ondas' ou de 'abrir o guarda-chuva', aonde cada um permanece no seu canto e a única estratégia bem afirmada é aquela de defesa do seu território.”

Outra característica que pode dificultar o processo de mudanças decorre das relações de poder. Mesmo que a autoridade formal possa estar claramente definida no organograma, as relações informais de poder, em hospitais gerais, seguem tradicionalmente a seguinte ordem: na linha de frente, detendo o conhecimento técnico, representando as atividades fins, estão os médicos e enfermeiros; em segundo plano, encontram-se os profissionais de apoio técnico, ou seja, aqueles ligados aos serviços de apoio diagnóstico e terapêutico; os terceiros, na escala informal, de poder ficam representados pelo corpo de apoio administrativo, (BARBOSA, 1995).

Mintzberg (2003) ao analisar as organizações profissionais (por exemplo, hospitais e universidades) e o papel dos administradores nesse contexto, afirma que, comparativamente às organizações industriais, tais executivos possuem menos poder, pois não são totalmente capazes de controlar os profissionais diretamente, sendo o poder exercido apenas de forma indireta. "The professional administrator maintains power only as long as the professionals perceive him or her to be serving their interests effectively.

A coordenação de esforços para as mudanças esbarra na própria estrutura de poder das instituições hospitalares. Por serem as configurações de estruturas descentralizadas, o corpo profissional (trata-se, segundo Mintzberg, Ahlstrand e Lampel (2004) dos experts: em hospitais, médicos e, em alguns casos, enfermeiras) não apenas controla seu próprio trabalho, mas detém grande controle coletivo sobre as decisões administrativas. Isso pode ser garantido, por exemplo, com a colocação de experts em cargos-chave da organização.

\section{Burocracia da Qualidade e Produtividade}

O Gerenciamento da Qualidade, essa nova abordagem gerencial, como é chamado por Scholtes (1992), permite que as empresas acompanhem as mudanças e até mesmo se antecipem a elas, pois enfatiza a melhoria contínua de produtos e serviços, pela utilização do método científico e monitorização de dados que embasam a tomada de decisões. Além disso, tem se mostrado útil em qualquer empresa, seja ela produtora de bens ou serviços, grande ou pequena, pública ou privada

A área de saúde, ainda que timidamente, despertou para a Qualidade nos anos 80 devido aos recursos financeiros cada vez menores e aos custos cada vez maiores, além de uma variada gama de pressões vindas do governo, da indústria, dos clientes, da rápida evolução da tecnologia médica. Esta nova situação, tem feito algumas instituições da área de saúde reavaliarem sua forma de administração e adotarem o Gerenciamento da Qualidade. Entretanto, principalmente aqui no Brasil, ainda não são muitas as instituições de saúde que se dispuseram a trilhar o caminho da Qualidade, adotando esta nova filosofia.

A enfermagem, a exemplo dos hospitais, também começa a estudar e a adotar o Gerenciamento da Qualidade com vistas a alcançar não só um padrão aceitável de assistência, mas também a atender as expectativas dos trabalhadores e dos pacientes. Contudo, aqui em nosso meio, as tentativas de implantação ainda são recentes e os estudos sobre o tema só agora começam a alcançar a amplitude necessária para que a comunidade da enfermagem possa conhecê-lo e utilizá-lo em sua prática administrativa.

Entendida como uma nova abordagem da administração, a Qualidade é marcada por princípios, ideias e crenças que buscam em última instância a satisfação dos clientes, dos trabalhadores (administração e funcionários), dos fornecedores e dos acionistas (Brocka \& Brocka, 1994).

O Gerenciamento da Qualidade (Total Quality Management - TQM) é um processo através do qual se busca implantar a filosofia da Qualidade Total, cuja principal finalidade é a melhoria contínua dos produtos ou 
serviços, pelo aprimoramento do trabalho dos diversos membros e de todas as áreas da organização. Ele utiliza conceitos da moderna administração, envolvimento e comprometimento das pessoas, introdução de inovações por sugestões e instrumentos de medida e de avaliação do trabalho, buscando a redução do desperdício pela utilização adequada dos recursos e o atendimento das necessidades do cliente pela melhoria dos processos de trabalho.

Um estudo de qualidade feito em hospitais americanos constatou que "as organizações de assistência à saúde não acreditam ainda que a melhoria da qualidade é, para elas, necessária à sobrevivência”. No Brasil, apesar da recente preocupação (mesmo que em casos isolados) em aprimorar os serviços de qualidade e melhor controlar os custos, há ainda grande dificuldade em aplicar e adequar o discurso de competitividade, concorrência e visão estratégica ao contexto hospitalar. A própria natureza da instituição pode trazer, em si, alguns entraves. Nesse sentido, a cultura da prática médica acaba por influenciar toda a organização, inclusive a sua prática administrativa. Conforme aponta o mesmo estudo já referido sobre qualidade em serviços de saúde, "falta-lhe (aos programas de qualidade) uma teoria geral sobre as fontes de risco nos complexos processos de serviço de saúde" (Berwick et al.,1994).

A Teoria da Qualidade proposta por Deming é bastante abrangente e representativa do pensamento da Qualidade, por isto serviu de base teórica para o estudo que ora apresentamos. Ela apresenta dentre outras coisas "Os 14 princípios de Deming", cada um com algumas recomendações, a partir dos quais elaboramos uma parte do instrumento de coleta de dados que utilizamos na pesquisa. Tais princípios são os seguintes:

- Crie constância de propósitos para melhoria do produto e do serviço

- $\quad$ Adote a nova filosofia

- $\quad$ Cesse a dependência da inspeção em massa

- Acabe com a prática de aprovar orçamentos apenas com base no preço

- Melhore constantemente o sistema de produção e de serviços

- Institua treinamento

- Adote e institua a liderança

- $\quad$ Afaste o medo

- Rompa as barreiras entre os diversos setores de pessoal

- Elimine slogans, exortações e metas para a mão de obra

- Suprima as cotas numéricas para a mão de obra

- Remova as barreiras que privam as pessoas do justo orgulho pelo trabalho bem executado

- Estimule a formação e o auto aprimoramento de todos

- Tome a iniciativa para realizar a transformação

Close (1997) em sua contribuição para o livro organizado por Morton-Cooper e Bamford, Excellence in Health Care Management 44, considera que a evolução do gerenciamento da qualidade na saúde, na última década, na Inglaterra, foi influenciada por:

- fatores políticos: a insatisfação do governo conservador com os custos e a resolutividade do sistema nacional de saúde; a introdução de avaliação de performance dos serviços; a constatação da pouca relação entre os serviços e as necessidades da população; a introdução, em 1990, da competição no setor saúde;

- educação: cursos de acreditação regulares; exames externos; indicadores de desempenho;

- profissionais: os conselhos garantem a qualidade dos profissionais e retiram os maus profissionais do mercado;

• consumidores: conselhos de saúde; a mídia; ONGs; representação de pacientes;

Close (1997) defende que a implementação satisfatória da estratégia da qualidade depende basicamente de dois fatores: reduzir a resistência e ter suporte de pessoas chave. O primeiro pode ser obtido a partir da disseminação de informações, estabelecimento de comunicação e envolvimento das pessoas no processo. $\mathrm{O}$ segundo está relacionado com a necessidade de vender a ideia às pessoas e a grupos chave. Para tanto, a organização deve "comunicar-se como nunca se comunicou antes", mudar as percepções de medo para oportunidade, fazer compromissos enérgicos com as pessoas e procurar envolver, o mais cedo possível, toda a organização.

Joint Commission Accreditation of Hospitals 48, que, já em 1979, reduziu os requisitos para a auditoria médica e adicionou a exigência de que os hospitais estabeleçam "programas" efetivos em garantia da qualidade. Diante da constatação de que as reais barreiras ao sucesso dos programas de qualidade não se encontram na dificuldade de levantar e analisar dados, e sim na resistência das pessoas, os autores apresentam dez obstáculos principais à mudança: 
- Expectativa de autonomia dos profissionais de saúde: devido à importância do trabalho desenvolvido pelos profissionais de saúde (altamente pessoal, lidando geralmente com questões críticas de vida, morte e sofrimento humano) e à exigência de uma base complexa de conhecimento e de tecnologia necessárias ao diagnóstico e tratamento, tais profissionais têm, tradicionalmente, assumido altos níveis de independência funcional. Assim, as expectativas de autonomia dos profissionais de saúde não apenas servem para minimizar a observação ao trabalho deles, mas, ainda mais importante, constituem uma fonte formidável de resistência à imposição de abordagens formais para assegurar a qualidade da assistência.

- Benefícios coletivos da estabilidade: as pessoas nas organizações, particularmente nas de saúde, tendem a desenvolver rotinas, procedimentos e formas prescritas de comunicação que acabam por determinar as formas de comportamento organizacional.

- Oposição calculada à mudança: está relacionada com a resistência organizada de indivíduos e grupos à mudança. Uma das causas pode estar relacionada com o reajuste das forças de poder, influência e status entre os níveis gerenciais.

- Comportamento programado: a programação do comportamento é feita de diversas formas. Métodos de programação estão, geralmente, relacionados com a divisão do trabalho (descrição do cargo e responsabilidades definidas e detalhadas), práticas de recrutamento e seleção, estruturas de recompensa, promoção, treinamento e outras atividades simbólicas. Apesar de considerarem essas funções como essenciais à instituição, os autores argumentam que o comportamento programado acaba por restringir a inovação.

- Visão limitada: problemas cotidianos dos profissionais de saúde assumem um nível tão desproporcional de importância que o comportamento resultante pode parecer petty 49 a observadores externos. $\mathrm{O}$ resultado é que as pessoas tenderão a perder a perspectiva do problema, ao ponto de "pequenos morros se assemelharem a gigantes montanhas". A divisão do trabalho em tarefas específicas, geralmente, produz tais resultados, de modo que a consideração meticulosa das regras institucionais se torna um caso de vida ou morte e aqueles envolvidos em pequenas tarefas perdem a perspectiva de como suas atividades se relacionam com os objetivos da organização. Para essas pessoas, o esforço de melhoria da qualidade pode parecer altamente ameaçador e destruidor. Tais resistências, segundo os autores, não são causadas por falta de inteligência ou de boas intenções dos profissionais de saúde, mas por estarem tão concentrados em suas funções especializadas que tendem a perder a visão das implicações maiores da inovação e da mudança.

- Limitação de recursos: a escassez de recursos torna as organizações menos fortes para a mudança.

- Custos perdidos: outra barreira sistêmica à mudança é o grande volume de investimentos sem retorno, sejam relacionados com investimentos de capital ou aquisição de conhecimentos.

- Acúmulo de restrições oficiais do comportamento: normas, regulamentações departamentais, políticas internas, manuais de operação e especificações detalhadas, apesar de reduzirem a injustiça devido à aplicação inconsistente de regras gerais, definem claramente o comportamento organizacional, nem sempre coerente com a abordagem inovadora dos programas de qualidade.

- Restrições não-oficiais e não planejadas do comportamento: a organização informal e suas relações de poder, particularmente quando vinculadas ao status dos profissionais de saúde, podem ameaçar a mudança por diversas formas sutis, porém efetivas, de ação.

- Acordos Inter organizacionais: incluem os acordos entre organizações e externos à instituição como contrato de trabalho e outros.

Shortell (1995) faz uma revisão e análise da literatura na área de saúde, entre 1991 e 1993, referente aos programas de qualidade, a partir de quatro dimensões: cultural (crenças, valores, normas e comportamentos), estratégica (vinculação dos programas de qualidade às estratégias globais da instituição), técnica (treinamento para as ferramentas da qualidade) e estrutural (entidades e grupos de tarefa destinados à implantação dos programas de qualidade) Por fim, são identificados, a partir desse modelo teórico, os principais obstáculos e desafios à implementação da qualidade nas instituições de saúde.

\section{Considerações finais}

A questão “Administração é ciência ou é arte?” tem sido perpetuada em classes / palestras introdutórias ou livros de teorias da administração com respostas não conclusivas, uma vez que "a Administração ainda se encontra numa fase amalgamada de ciência e arte.” (Mattos, 2009). Se a Administração se encontra numa fase interdisciplinar, faz-se interessante pensarmos se seria possível a aplicação de métodos científicos e limitadores da capacidade humana, como Taylor propôs, na Administração contemporânea. Taylor citado por Batista dos Santos e Nepomuceno (2009), já admitia que o trabalhador não era ignorante, ao contrário, reconhecia a inteligência desse, assumindo que as experiências de cada geração constroem melhores 
procedimentos e métodos práticos, porém, no método Taylorista, não é o operário quem deveria decidir qual método mais adequado para seu trabalho, mas o gerente.

Analisando as teorias administrativas e a evolução das mesmas, conclui-se que as proposições não são antagônicas, mas se completam. Assim, cada instabilidade encontrada nessas tem sido aprimorada por novas teorias, desenvolvidas até os dias atuais, adaptadas ao cenário vigente de sua formulação.

O capitalismo moderno tem determinado que as atividades intelectuais e de comunicação integrem crescentemente todos os níveis das atividades produtivas, incluindo os trabalhadores da linha de produção, e exigindo que esses sejam polivalentes, ou seja, carece de uma aliança entre a produtividade e a capacidade humana dos operários. Wood Junior (1992) enfatiza que o modelo organizacional deve agregar especialização técnica, coordenação, sincronismo incrementadas com arte. Atendendo a essa demanda, a gestão participativa surge como um avanço da concepção mecanicista em direção às propostas das organizações flexíveis: unindo a racionalização da produção capitalista (de acordo com as Teorias Clássicas) com as sugestões dadas pelos trabalhadores (criatividade e produção intelectual humana).

Podemos concluir que as práticas administrativas têm carecido e buscado a união dos pontos positivos de cada teoria, adaptando essas ao cenário vigente e acrescendo a essas práticas o toque da arte administrativa que toda organização necessita.

Diante da peculiaridade do processo de mudança estratégica no ambiente hospitalar, justifica-se também discutir a ação e a contribuição dos gestores na superação das dificuldades e entraves do processo. Assim, busca-se avaliar sua real e efetiva contribuição enquanto agente catalisador e facilitador da mudança. O correto diagnóstico do processo de mudança em instituições hospitalares subsidiará a elaboração de estratégias de ação e a proposição de alternativas que objetivem facilitar o processo de mudança e garantir a sua eficácia em longo prazo.

Por fim, o administrador precisa conhecer os aspectos éticos e legais que envolvem essa instituição, que se deriva do direito a "saúde para todos", onde a dignidade da pessoa deve ser respeitada e o atendimento deve ser garantido, ter conhecimento de todas as funções que envolvem o hospital e compreender a visão do conjunto por completo, que são: manutenção da saúde, prevenção da doença, educação profissional e pesquisa. No entanto, assiste a esse administrador a tarefa de procurar aliar essas funções aos recursos disponíveis da instituição.

\section{Referências}

Azevedo, C. S. 1993. Gerência hospitalar: a visão dos diretores de hospitais públicos do município do Rio de Janeiro. Dissertação de mestrado (Instituto de Medicina Social). Rio de Janeiro, RJ: Universidade Federal do Rio Janeiro.

Barbosa, A. P. 1995. Qualidade em Serviços de Saúde. Dissertação de mestrado (Escola de Administração de Empresas). São Paulo, SP: Fundação Getulio Vargas.

Batista dos Santos, A. C., \& Nepomuceno, L. H. 2009. Trabalhador na Teoria Organizacional e Administrativa: uma Revisão Bibliográfica Crítica dos Fundamentos e da Atualidade do Pensamento Taylorista. Disponível em: <anabatistaufersa.googlepages.com/artigocongepemdeTayloraAO.pdf>.

Berwick, D. M., Godfrey, A. B., \& Roessner, J. 1994. Melhorando a Qualidade dos Serviços Médicos, Hospitalares e da Saúde. São Paulo, SP: Makron Books.

Burmester, H., \& Richard, J. P. 1995. Planejamento e Gerência Estratégicos. In: R.M. Castelar, P. Mordelet. Gestão Hospitalar: um Desafio para o Hospital Brasileiro. Rennes, FR: Ecole National de la Sante Publique.

Chiavenato, I. 1997. Teoria Geral da Administração. Abordagens prescritivas e normativas da administração (5a ed.) São Paulo, SP: Makron Books.

Chiavenato, I. 1989. Gestão de Pessoas; Um Novo Papel dos Recursos Humanos nas Organizações (1a ed.). Rio de Janeiro, RJ: Ed. Campus.

Close, A. 1997. Quality management in health care and health care education. Excellence in Health Care Management. Oxford: Blackwell Science, 75-112.

Earl, M. J. 1989. Management Strategies for Information Technology.

Freitas, H. M. R. 1994. Sistemas de Informações Gerenciais e de Apoio à Decisão. Porto Alegre, RS: PPFA/UFRGS

Laudon, K. C., \& Laudon, J. P. 1997. Management Information Systems: Organization and Technology. In M.K. Stumpf, \& H.M.R. Freitas. A Gestão da Informação em um Hospital Universitário: O Processo de Definição do Patient Core Record. Revista de Administração Contemporânea, 1(1). 
Mattos, P. L.C. L. 2009. Administração é ciência ou arte? O que podemos aprender com este mal-entendido?, $R A E, 49(3)$.

Mintzberg, H. 2003. Criando organizações eficazes: estruturas em cinco configurações (2a ed.). São Paulo, SP: Atlas.

Mintzberg, H., Ahlstrand, B., \& Lampel, J. 2004. Safári de estratégia (2a ed.). Porto Alegre, RS: Bookman.

Motta, F. C. P. 1085. Teoria Geral de Administração (12a ed.). São Paulo, SP: Pioneira.

Ortiz, R. 1997. Informação e conhecimento. Sao Paulo, SP: Folha de S. Paulo.

Shortell, S. M. 1995. Assessing the evidence on CQI. Hospital \& Health Services Administration, 40(1).

Stoner, R. 1999. Teoria Geral da Administração. São Paulo, SP: Makron Books.

Stumpf, M. K., \& Freitas, H. M. R. 1997. A Gestão da Informação em um Hospital Universitário: OProcesso de Definição do Patient Core Record. Revista de Administração Contemporânea, 1(1), 71-99.

Torres, N A. 1995. Competitividade empresarial com a tecnologia da informação. São Paulo, SP: Makron Books. Ward, C. 1997. Quality Finance and Information Management. Excellence in Health Care Management, 113-135.

Wood Junior., T. 1992. Fordismo, toyotismo e volvismo - os caminhos da indústria em busca do tempo perdido. Revista de Administração de Empresas, 34(2), 6-18.

\section{Minicurrículo}

José Angelo Leal Braga. Mestre em Terapia Intensiva pela Sociedade Brasileira de Terapia Intensiva, PósGraduado em Terapia Intensiva pelo Instituto Brasileiro de Terapia Intensiva (IBRATI), Especialista em Enfermagem do Trabalho pelo Centro Universitário São Camilo, Especialista em Administração Hospitalar pela Secretaria Estadual de Saúde do Rio de Janeiro, Graduado em Enfermagem pelo Centro Universitário Serra dos Órgãos - UNIFESO. Docente e Preceptor do Curso de Graduação em Enfermagem do Centro Universitário Serra dos Órgãos - UNIFESO. Membro da Sociedade Brasileira de Medicina Intensiva e Membro da ERWS (Emergency Rescue World Society).

Como citar: Braga, J.A.L. 2020. O enfermeiro diante da burocracia da qualidade e produtividade no ambiente hospitalar. Pubsaúde, 3, a020. DOI: https:// dx.doi.org/10.31533/pubsaude3.a020

Recebido: 29 jan. 2020.

Revisado e aceito: 18 mar. 2020.

Conflito de interesse: os autores declaram, em relação aos produtos e companhias descritos nesse artigo, não ter interesses associativos, comerciais, de propriedade ou financeiros que representem conflito de interesse.

Licenciamento: Este artigo é publicado na modalidade Acesso Aberto sob a licença Creative Commons Atribuição 4.0 (CC-BY 4.0). 